\title{
SUSPEN DOME: AN EVALUATION WITH CFRP CABLES
}

\author{
IfeOlorun Olofin and Ronggui Liu \\ Jiangsu University, FacultyofCivil Engineering and Mechanics,Zhenjiang, No 301 \\ Xuefu road, China; epher2002@yahoo.com
}

\begin{abstract}
This study investigated the feasibility of using CFRP cable as tension cables in suspen domes in view of the fact that suspen domes have been made with steel cables as its cable-strut system for centuries due to its availability. Indisputably, CFRP cables have become the material of choice in the $21^{\text {st }}$ century for its efficiency and innovative design in bridge works. However, the application of CFRP cables to other cable structures has been limited. The need for its application to other cable structures is required in order to acquire more knowledge about its behavioral patterns. This paper gives preliminary findings of a successfully designed and constructed suspen dome prototype which comprehensively deepens the understanding of CFRP cable performance as a cable-strut system in a suspen dome. Results show that with its high stiffness, low weight and high strength, CFRP has proven to be a technically efficient and adequately strengthening material for structurally improving the adequacy of a suspen dome.
\end{abstract}

\section{KEYWORDS}

Cable structures, Suspen dome, Cable-strut system, CFRP cable, Steel cable

\section{INTRODUCTION}

The trend for large span structures has become a preferred demand in the construction world today. New materials are searched for by Civil Engineers to construct lightweight structures with remarkable strength in the structure design of large span structures. Long span structures subjected to tension use cables for support. Some common cable structures include those illustrated in Figures. 1(a) and (b), to mention a few.

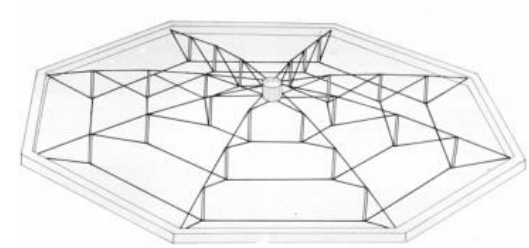

(a) Cable-stayed

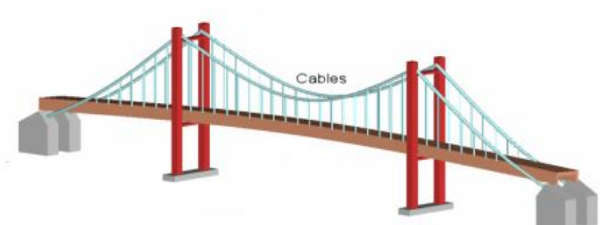

(b) Suspension bridge

Fig. 1- Cable-supported structures (Source: Google search)

An interconnected structure made up of a single reticulated shell and a tensegric system (strut and cable) as shown in Figures. 2(a) and (b) is known as a suspen dome. A cable-strut system is made up of tension and compressive member, where the radial and hoop are in tension and the strut in compression [1]. A Suspen-dome can be categorized as a cable stayed roof and also as a large span structure. The cable system within the suspen dome structure plays a key role in achieving longer span for the structure. 


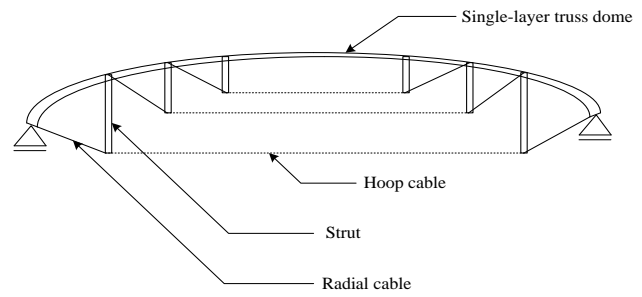

(a) Single reticulated shell and the cable-strut system [1]

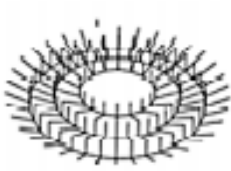

Cable strut
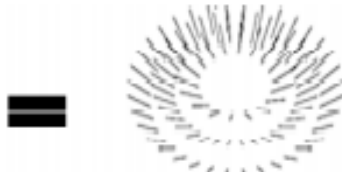

Radial cables

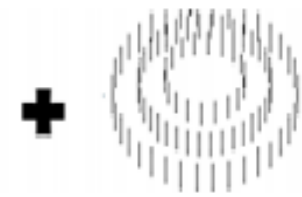

Strut

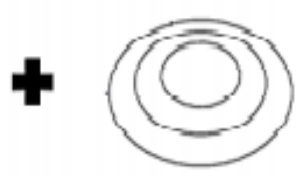

Hoop cables

(b) Details of a cable strut system [2]

Fig. 2- Suspen dome

It is known from literature that the cable-strut system of a suspen dome has only been constructed with steel cables [2]. Structural stability is a key problem in the design of steel structures. The high tensile strength of steel cables is an ideal structural element for long span structure but in situations where much longer distances are required one has to resort to applying a new material. For Civil engineering works composite materials are mostly used as replacement. A CFRP cable has properties of high strength, corrosion resistance, low maintenance requirement, light weight and low relaxation compared to steel cables. With the development and implementation of CFRP cables, researchers are becoming inclined in its use for bridge engineering [3].

This paper gives a general evaluation based on the findings on static behaviour of both steel and CFRP obtained from analysis of a successfully built prototype of a suspen dome with CFRP cables as the cable-strut system, despite its anchorage challenges, compared with analytical results of steel cables.

\section{A REVIEW ON EXISTING ROOF STRUCTURES WITH CFRP CABLE}

In today's world, new innovations are prominent for designing and constructing structures. As mentioned earlier, CFRP cables in real life architecture are mostly implemented in bridges [410]. Up till now, there are no existing cable structures other than bridges on large scale with CFRP cables. In reality, the studies of CFRP cables used in other cables structures are meagre. Hence, limited information can be gathered on such topic. However, Schlaich et al[11] researched on the utilization of CFRP tension members and their anchorage for a cable roof. Similarly, an orthogonally cable structure was constructed with CFRP cables by Brennd el al [12] and Yue et al.[13] though in a miniature scope to provide positive effect and elasticity of CFRP cables (Figure 3). 


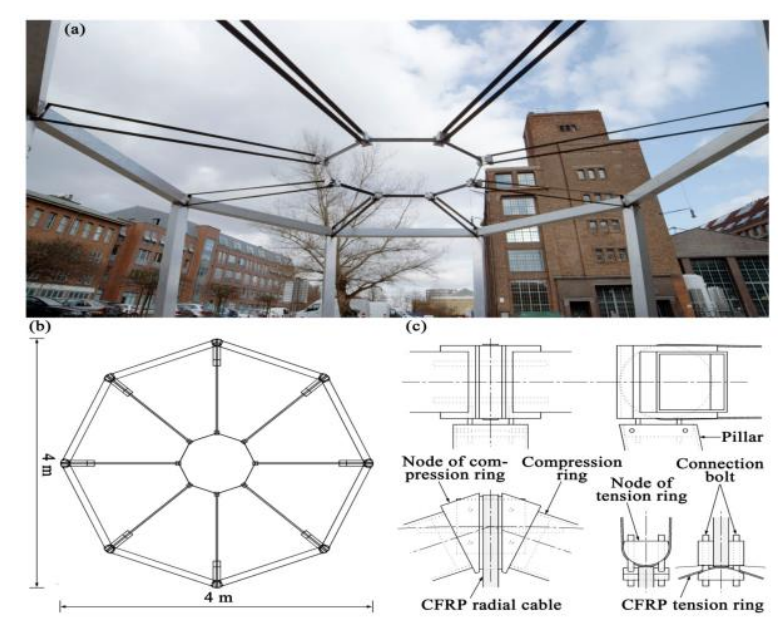

a) Plan view, compression and tension rings nodes of CFRP spoked wheel roof

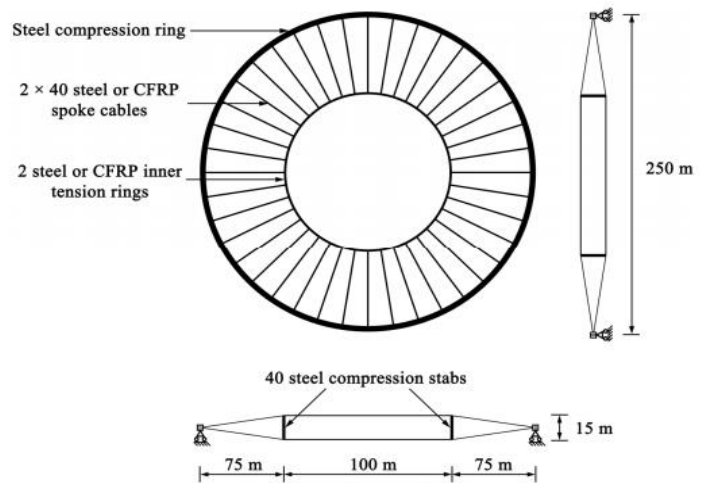

b) Design and restraint conditions for a spoked wheel cable roof

Fig 3. - Spoked wheel cable [13]

The researchers ascertained that CFRP cable can improve the economic efficiency of façade cable roof. In addition, increasing the structural stiffness can improve the stability of the spoked wheel cable roof. Analogously, Olofin and Liu. [14-16] verified the implementation of CFRP cables in lieu of steel in a suspen dome numerically to understand the behavioral pattern of the structure. In addition, a computational analysis on the peak bearing capacity of an existing suspen dome was analyzed to justify outcomes [17] (Figure 4).

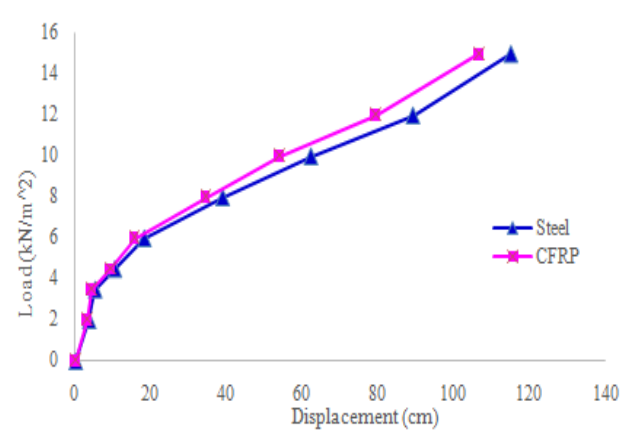

Fig 4. - Load-displacement comparison [17]

With the numerical results, experimentation on the static behavior of a prototype was investigated to verify the numerical findings [18]. The analyst concluded that CFRP gave outstanding performance which improved the structural efficiency of the cable-strut system as steel 
cables. Hence using CFRP cables as a cable-strut system in a suspen dome is an important future development.

\section{ANCHORAGE SYSTEM}

Based on finite element analysis and bond theory, analysis and design of an anchor for CFRP was established. Due to the fact that anchoring of CFRP cable is one of the challenging factors for its utilization [19], the anchorage system was drafted to allow load transfer and minimal creep under a maximal cable prestressing strength.

\section{LAYOUT OF THE ANCHORAGE}

A conical hole of $24 \mathrm{~mm} \times 16.5 \mathrm{~mm}$, a distance of $150 \mathrm{~mm}$ made with Q235 steel was established for the outer sleeve cylinder steel. The interior surface of the hole was $8.1 \mathrm{~mm}$, in order to effect the motion due to friction between the exterior sleeve and interior wedge lubricant was added as exemplify in Figure 5.

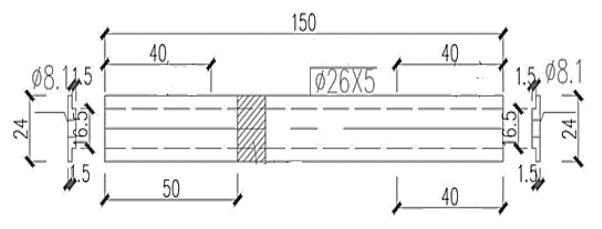

(a) Hoop cable anchorage

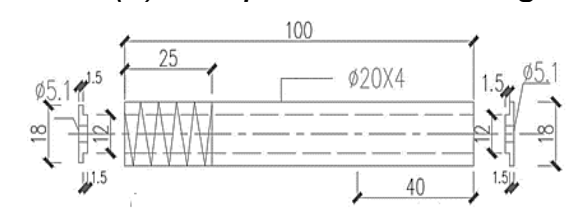

(b) Radial cable anchorage

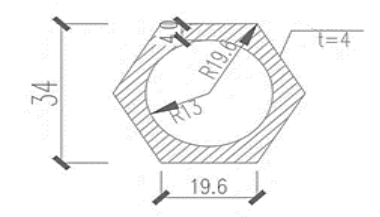

(c) Hexagonal nut

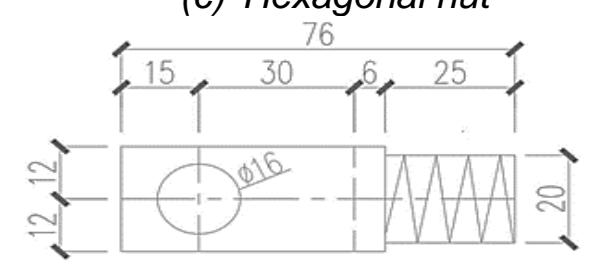

(d) Connector

Fig. 5 - Anchorage system

The CFRP anchor with connectors had a length of $151 \mathrm{~mm}$ and width of $24 \mathrm{~mm}$. The connector length is $76 \mathrm{~mm}$ and $24 \mathrm{~mm}$ in width, spiralling though a hexagonal bolt of $25 \mathrm{~mm}$. The design criteria for the sleeve is $18 \mathrm{~mm} \times 12 \mathrm{~mm}$, with the interior thread as $18 \mathrm{~mm}$ and exterior sleeve as $25 \mathrm{~mm}$.

\section{ANCHORAGE TEST}

Using a tensile machine, a uni-axial tensile test was investigated on samples to determine the anchorage mechanism; results obtained was slip failure (Figure 6) and colloid interference. 


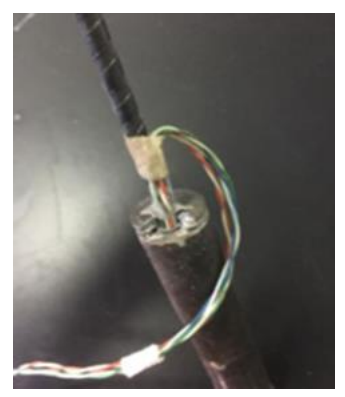

Fig. 6 - Slip failure

Similarly, based on bond stress distribution, the mechanism of the loading process on the cable showed that the bending moment for CFRP was small when axial tensile force was measured which is acceptable for further investigation for the utilization of CFRP cables as tension members in tensegrity system for a suspen dome.

\section{DESCRIPTION OF THE INVESTIGATED STRUCTURE}

The design of the model was generally carried out in accordance with Chinese specification [20-21]. The model comprises of three interlacement, the beam, column and the single reticulated shell as illustrated in Figure 7(a) and detailed dimensions in Table 1.

Tab 1 - Model dimensions

\begin{tabular}{|l|l|l|l|}
\hline Sections & $\begin{array}{l}\text { Height } \\
(\mathrm{m})\end{array}$ & $\begin{array}{l}\text { Cross-sectional } \\
\text { area }(\mathrm{m})\end{array}$ & Diameter $(\mathrm{mm})$ \\
\hline $\begin{array}{l}\text { Reticulated system } \\
\text { with steel bars }\end{array}$ & 0.4 & $20 \times 12$ & 4 \\
\hline Columns & 1.5 & $102 \times 8$ & - \\
\hline Circular beams & - & $\begin{array}{l}\mathrm{H} 200 \times 200 \times 8 \times \\
12\end{array}$ & 4 \\
\hline Inner hoop & - & - & 1.2 \\
\hline Outer hoop & - & - & 2.6 \\
\hline
\end{tabular}

The reliability, stiffness and strength of the joint was designed appropriately to avoid joint displacement due to brakeage not to affect the property mechanically. Figure 7(b). illustrates the joint connection for the proposed prototype.

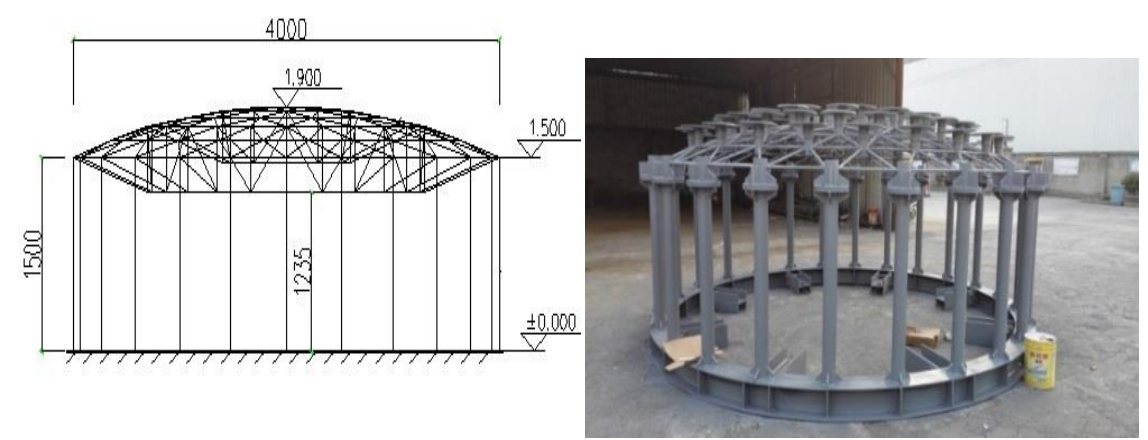

(a) Model 


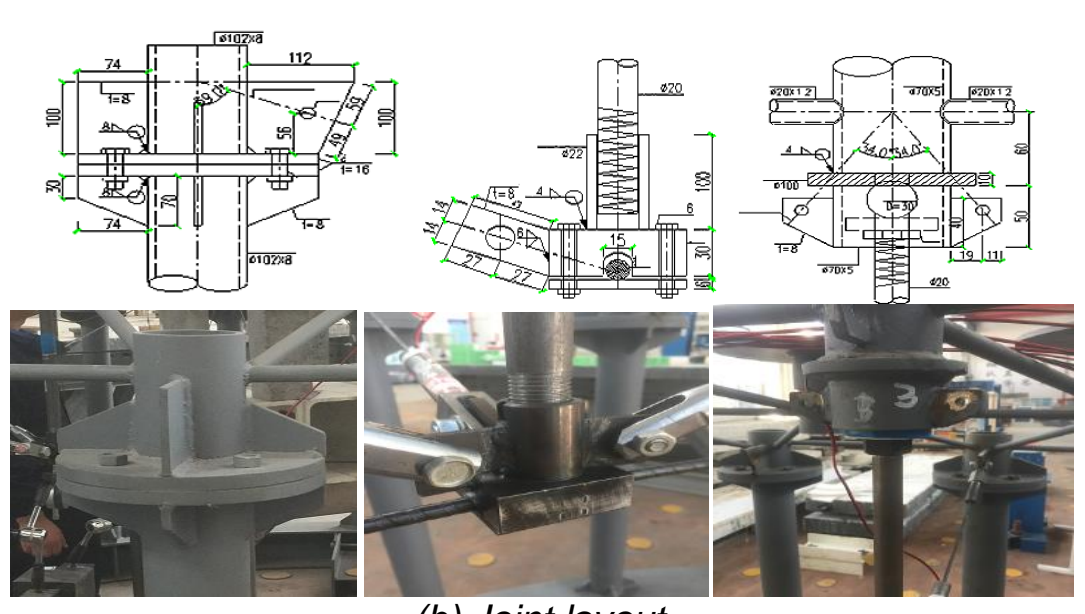

(b) Joint layout

Fig. 7 - Description of the prototype

An ideal elasto-plasticity Q235 steel was used for the reticulated single layer and column whereas the cables are elastic.

\section{MATERIAL PARAMETER} model.

Table 2 illustrates the material parameters used for the construction and simulation of the

Tab 2 - Material Parameters

\begin{tabular}{|l|l|l|l|}
\hline Material & Density $\left(\mathrm{kg} / \mathrm{m}^{3}\right)$ & $\begin{array}{l}\text { Modulus of } \\
\text { Elasticity(MPa) }\end{array}$ & $\begin{array}{l}\text { Tensile } \\
\text { tension(MPa) }\end{array}$ \\
\hline Steel & 7850 & 180 & 835 \\
\hline CFRP(Hoop cable) & 1600 & 147 & 2550 \\
\hline CFRP(Radial cable) & 1600 & 132 & 1528 \\
\hline
\end{tabular}

\section{INTERNAL FORCE MEASUREMENT IN CABLE MEMBERS}

Tension sensor was used to measure the internal force produced in the hoop cable and strain gauge for the radial cable. The arrangement of the tension sensor on the hoop cable is illustrated in Figure 8(a) and the strain gauges were arranged as illustrated in Figure 8(b). The combination of tension sensor and strain gauge was used to measure tension in the cable. For the prestressed cables, thread sleeve method was employed with the scene layout illustrated in Figure 8 (c) showing radial cable and hoop cable which was tensioned at $3 \mathrm{kN}$. 


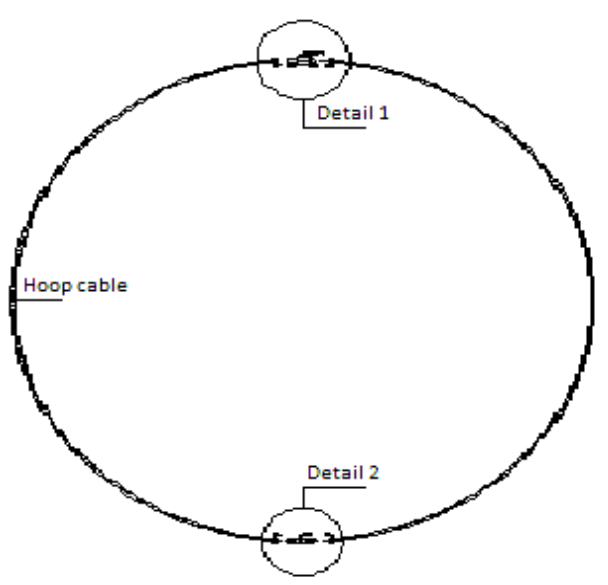

(a) Hoop cable overview

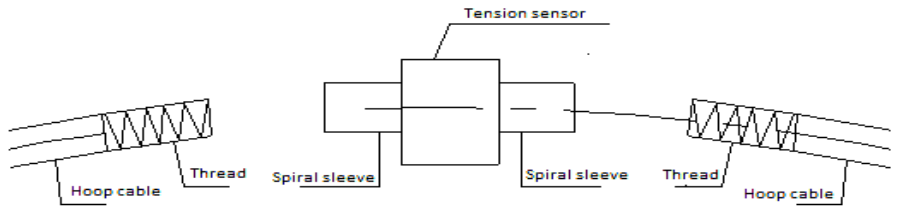

i) Detail 1

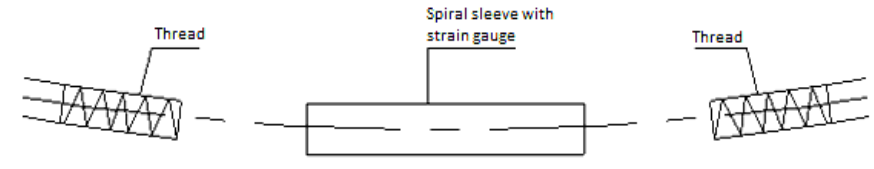

ii) Detail 2

(b) Detail layout

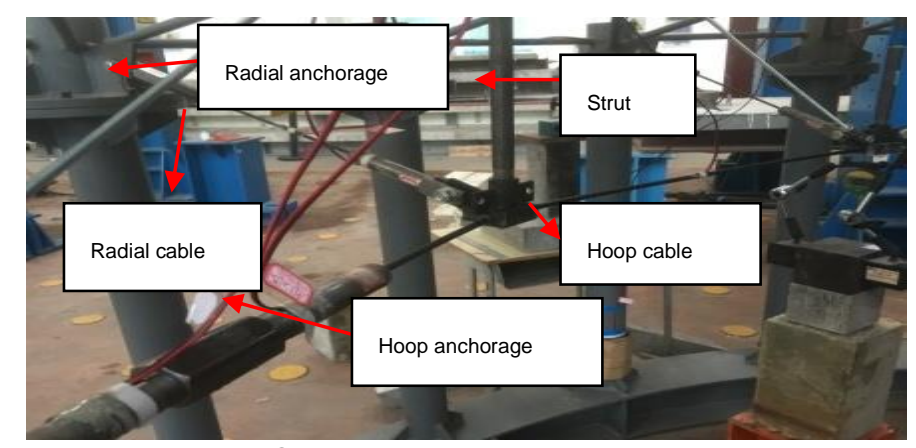

(c) Implementation of CFRP cables in the outer hoop and radial member

Fig. 8 - Outline of the cable members

Based on the findings of Kang et al. [22] which states that the maximum tension on the reticulated single layer are produced and intensive near the support of the hoop and radial cable, the experimentation CFRP cables were only applied for tension members which are the radial and hoop cable as illustrated in Figure 8 . The hoop cables are $8 \mathrm{~mm}$ in diameter and radial $5 \mathrm{~mm}$ in diameter for CFRP.

\section{LOADING AND BOUNDARY CONDITIONS}

The dead, live, seismic and temperature are considered alongside with all pertinent load combinations as specified in Chinese standard codes for structures [20-21]. The single reticulated 


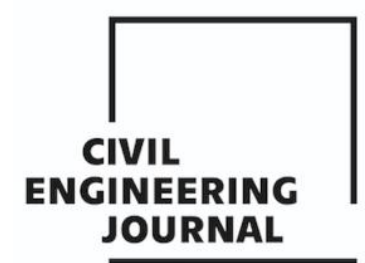

Article no. 34

THE CIVIL ENGINEERING JOURNAL 2-2021

shells are under uniform loads and joints are rigid. The degrees of freedom for the supporting joints are restricted and assumed as pin jointed.

\section{NUMERICAL TECHNIQUE FOR THE MODEL}

In this study, an FEM software namely ANSYS was used to investigate the model to gather numerical data in comparison to the experimental data for validation of the test model. Trusses and beams are the fundamental composite of a suspen dome; BEAM188 was implemented for the single reticulated shell while LINK 10 was for the cable members [23]. A mesh size of $1 \mathrm{~mm}$ was adopted. Uniformly distributed load is equivalent to a vertical concentrated load based on the equivalent principle of static. (Figure 9).

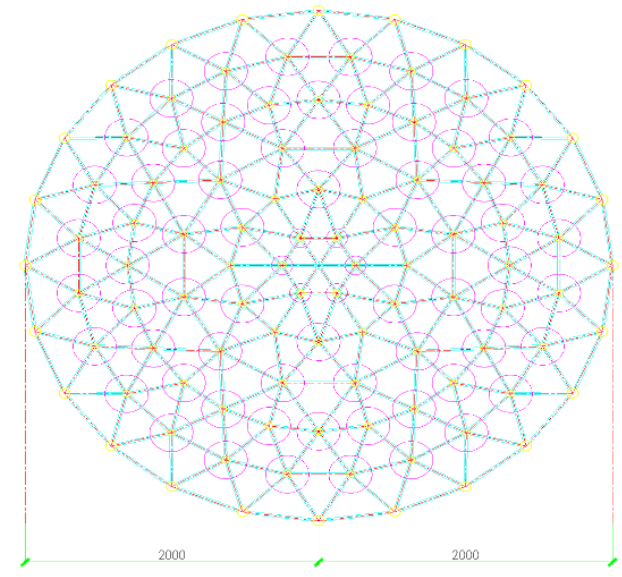

Fig. 9 - Numerical load setup for the single reticulated shell

Numerical simulation was investigated on CFRP and steel cables to make juxtaposition with the experimental data collected for CFRP cable. Full span loading was considered based on literature by Guo et al [24] to better understand the static behavior of the system.

\section{EXPERIMENTAL PROCEDURE FOR THE MODEL}

Three stages were involved for the test model setup which are i) installation i.e levelling, ii) geometric parameter measurement which entails measuring span, height, diameter to determine preliminary geometric imperfection of the prototype and iii) material limit dimension which entails test been carried out to determine tensile strength of the cables. The tests are specified into three categorizes i) deflection test, ii) strain test and (iii) the test of internal force produced in the cables. The measuring devices are i) displacement laser tracker and ii) TS3862 static resistance strain measurer (Figure 10 illustrates measuring points).

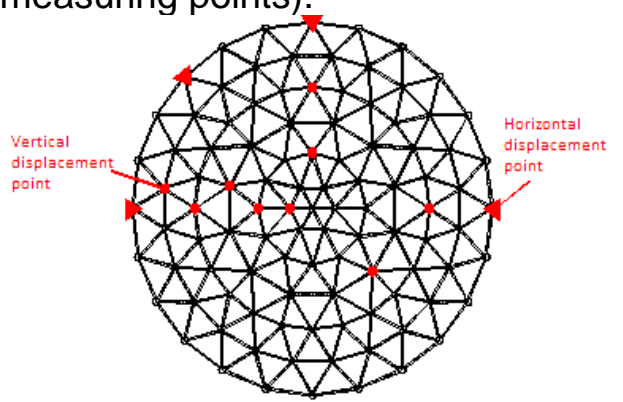

(a) Displacement measuring point 


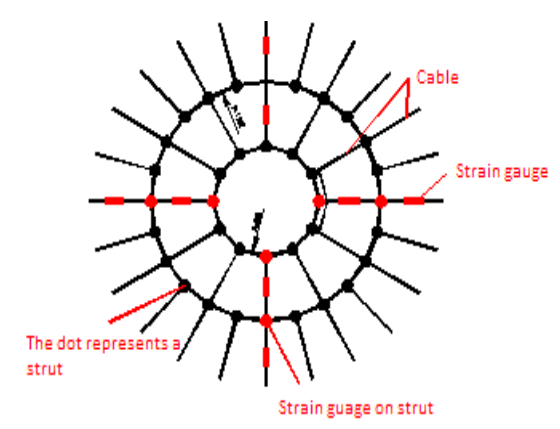

(b) Cable-strut system strain gauge layout

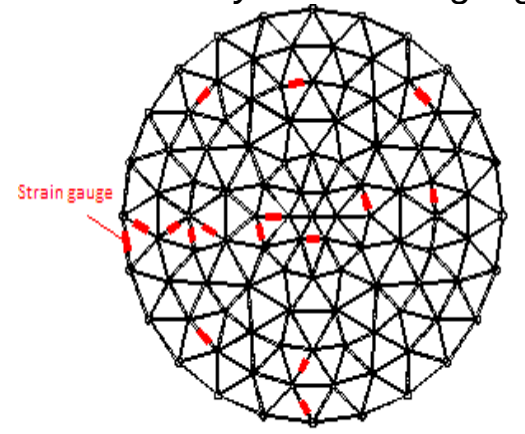

(c) Single reticulated shell strain gauge layout

Fig. 10 - Measuring points

\section{SUSPEN-DOME WITH CFRP CABLES PROTOTYPE}

Figure 11 illustrates the state of the art model with CFRP as the tensegrity system under full span loading. Based on Chinese specification, the test model was loaded symmetrically and unsymmetrically. Several loading processes were considered during the experimental measurement. The design requirements are specified in terms of the maximum load the structure must withstand.

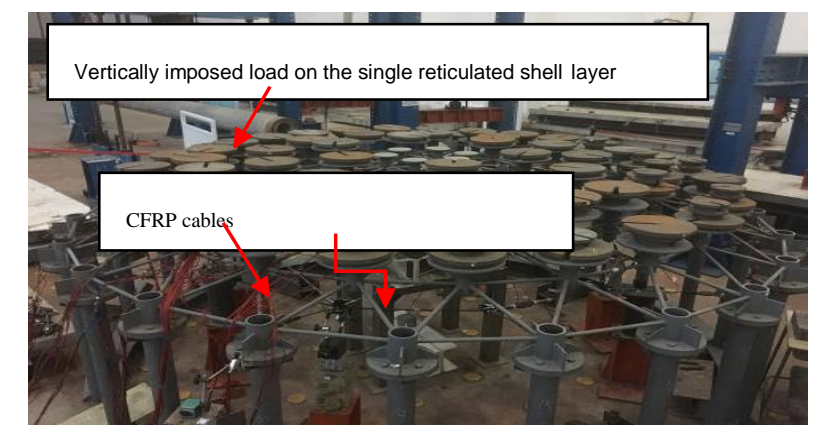

Fig. 11- Full span loading

Pretensioning of the cables were carried out by tightening the bolt at $180^{\circ}$ conservatively at intervals. Full span loading of $10 \mathrm{~kg}$ was considered in this study to justify that concentrated loads on CFRP cables has similar attributes as the traditional steel which can optimize the cable-strut system of a suspen dome.

\section{RESULTS AND DISCUSSION}


From Figure 12, it can be observed that the maximum displacement obtained for CFRP experimentally conforms to that of the numerical result of steel and CFRP. The little disparity, which is negligible, is believed to be the influence of the experiment surrounding.

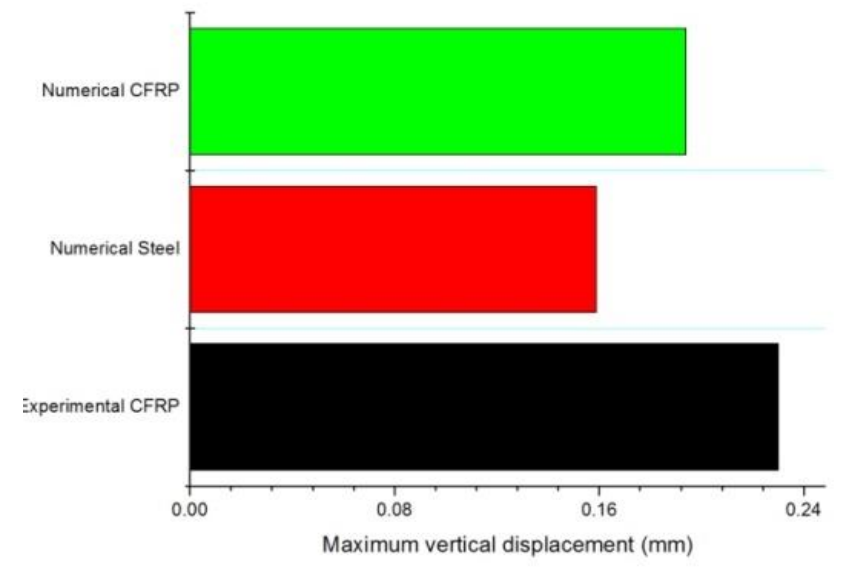

Fig. 12 - Maximum vertical displacement

Hence, it can be deduce that the measured displacement value of CFRP cable conforms to the allowable displacement specification for a tensegrity which should be $1 / 400$ (I is the span of the dome) [20].

\section{COMPARATIVE ANALYSIS OF MAXIMUM STRESS GENERATED IN THE SINGLE RETICULATED SHELL} stresses.

Under full span loading, the single reticulated shell bars were exposed to compressive

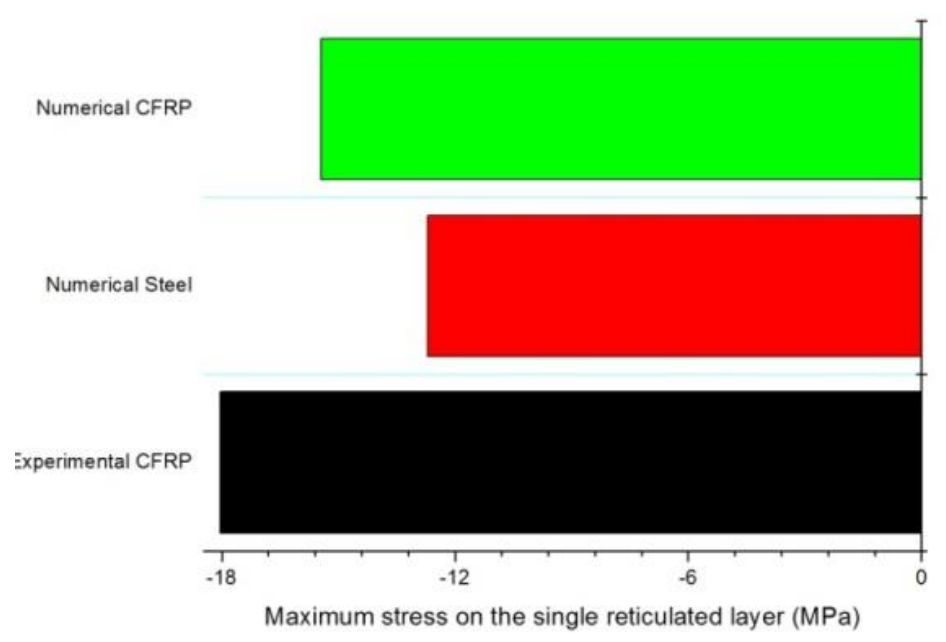

Fig. 13 - Maximum stress of the single reticulated shell

The trend of the stresses obtained from the experimentation with CFRP was similar to that of the FEM analysis as illustrated in Figure 13. 
COMPARATIVE ANALYSIS OF INTERNAL FORCES GENERATED IN THE OUTER HOOP CABLE

The internal force generated for CFRP for the experimentation has about $50 \%$ percentage difference from the numerical results of steel and CFRP as illustrated in Figure 14.

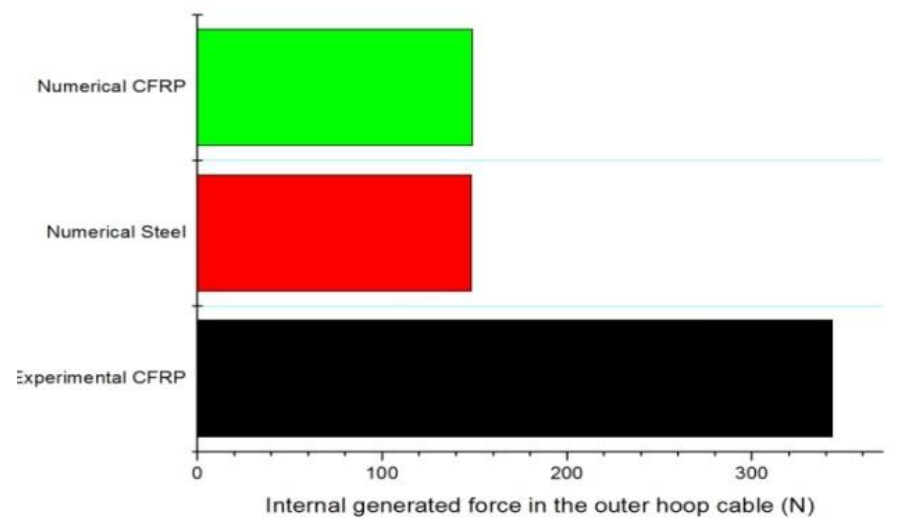

Fig. 14 - Comparison of internal generated force in the hoop cable

The possibility will be to adjust the pretension of the cables to lower the internal forces in the hoop cable or it could be as a result of the influence due to gauge position, shape of members and installing errors. Sometimes such errors may be compensated to produce accurate results.

\section{COMPARATIVE ANALYSIS OF RADIAL CABLES NEAR THE OUTER HOOP}

The pretensioning of the hoop cables directly produced the internal forces in the radial cables. Changes in the radial cable generated force is basically indistinguishable to that of the hoop cable.

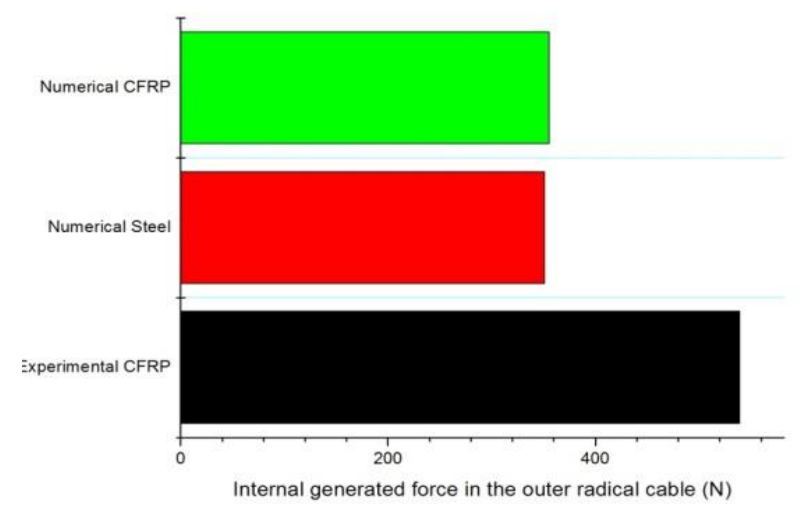

Fig. 15 - Internal generated force in the radial cables

Figure 15 illustrates the internal produced force in the radial cables. Due to the high internal force in the hoop cables, the radial cables have similar percentage difference. The difference in the measured and calculated forces could be also caused by little movement in the nodes of the actual structure.

\section{ANALYSIS OF ANCHORAGE SYSTEM}

The strain changes increase with rise in load. For the radial cable at initial loading the strain was $75 \mu \varepsilon$ and increased to $630 \mu \varepsilon$. Similarly, the hoop cable had a value of $-50 \mu \varepsilon$ initially and increased to $37 \mu \varepsilon$. 


\section{HOOP AND RADIAL CABLE ANCHOR}

Based on the ascribed loads, the strain changes in the anchor system for the radial and hoop cable conform to bond theory. The positioning of the strain gauge in the hoop cable for the anchor is exemplified in Figure 16, the strain gauge model is BX120-2AA.

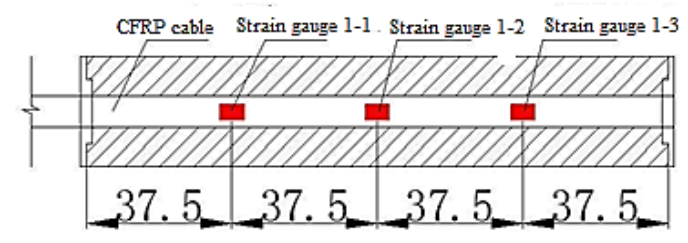

Fig. 16 - The hoop cable anchor with strain gauge (dimensions: $\mathrm{mm}$ )

The anchor consists of a three-piece strain gauge placed with adhesive and wired up to facilitate data collection. The radial cable is thinner since its diameter is $5 \mathrm{~mm}$, a smaller version of the strain gauge was used namely BX120-1AA. The three-piece strain gauge is enclosed firmly in the anchorage system as illustrated in Figure 17.

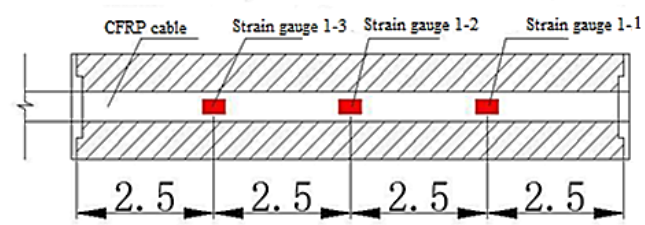

Fig. 17 - The radial cable anchor with strain gauge (dimensions: $\mathrm{mm}$ )

Table 3 illustrates the stresses generated in the anchorage system. Theoretically, the higher the prestressing force, the stress compression in the hoop cable approaches the anchoring node.

Tab 3 - Average stress generated in the anchorage system

\begin{tabular}{|l|l|l|}
\hline Strain gauge position & $\begin{array}{l}\text { Stress generated in hoop } \\
\text { anchor(MPa) }\end{array}$ & $\begin{array}{l}\text { Stress generated in radial } \\
\text { anchor(MPa) }\end{array}$ \\
\hline $1-1,1-2,1-3$ & 118.20 & 52.80 \\
\hline
\end{tabular}

Based on bond stress distribution, the result in Table 3 shows that the performance of the cable is indistinguishable to the axial pull reflecting the impact on the hoop cable is minimal and does not influence the anchorage. Similarly, the stress distribution of the radial cable is analogous to the stress distribution due to axial tension. The anchoring for the radial cable has exceptional stress resisting capability under loading conditions.

\section{CONCLUSION}

First of all, CFRP cables as the tensegrity system for a suspen dome has been constructed though on a small scale despite the challenges of anchorage. The findings obtained gave some ideas about the structural static stability of CFRP cables as a cable-strut system in a suspen dome.

Secondly, the obtained simulated results validate the test model which gives a practical design for the suspen dome with CFRP cables. The stresses on the single reticulated shell layer, the internal forces of the hoop and radial cables and the overall displacements fall within the range of the defined code which entails that the bending moment is minute when carbon fibre reinforced polymer cable is subjected to axial tensile force. Based on the setup procedure and the results 


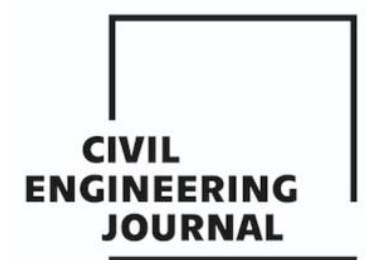

Article no. 34

THE CIVIL ENGINEERING JOURNAL 2-2021

gathered from the assembled prototype design, a real life large span suspen dome with CFRP cables as the cable-strut system can be erected in the future.

Finally, the information generated by the study could be used by researchers and engineers to upgrade and improve the design process of CFRP in cable structures for structural engineering works.

\section{ACKNOWLEDGEMENT}

The support of the National Science Foundation of China (Grant no: $51608234 ; 51478209$ ) and Province Science of Jiangsu BK20160534 are acknowledged by the authors

\section{REFERENCES}

[1] Subramanian, N. 2006 "Space Structures: Principles and Practice", Multi-Science Publishing Co Ltd, Brentwood, Essex, UK.

[2] Olofin, I. \& Liu, R. 2012. "Suspen-dome System: A Fascinating space Structure". The Open Journal of Civil Engineering. 11: 131-142

[3] Olofin, I. \& Liu, R. 2015“The Application of CFRP (CFRP) Cables in Civil Engineering Structures”. SSRG International Journal of Civil Engineering 2: 1-5.

[4] Meier, U.2000 "Composite materials in bridge repair". Applied Composite Material. 7: 75-94.

[5] Meier, U.1995 "Extending the life of cables by the use of carbon fibres". International Association for Bridge and Structural Engineering.

[6] Wen, X., Cai, C. S., Yin, Z., Rucheng, X.2011 "Study of Super long Span cable stayed Bridges with CFRP components". Engineering Structure. 33,330-343.

[7] Adanur, S., Gunaydin, M., Altunisik, A.C., Seuim, B. 2012“Dynamic behavior of a cable stayed bridge using CFRP cables". Vienna Congress on Recent Advances in Earthquake Engineering and Structural Dynamics.

[8] Filiphbanck, O.R.A..2014 "Application of CFRP cables in super long span cable supported bridge: A feasibility study" . Chalmers University of Technology.

[9] Guoying, F., Ronggui ,L., Bei, C." 2013Static Characteristics Analysis of cable-stayed bridges using CFRP cable". IJCTT. 4: 861-866.

[10] Meier, U. 1992“Carbon Fibre-Reinforced Polymers: modern materials in bridge engineering”. Struct. Eng.Int .DOI :101686692780617020.

[11] Schlaich, M., Bernd, Z., Yue L., \& Goller, R.2012“CFRP tension elements and their anchorages". Bautechnik. 89. 841-849.

[12] Bernd, Z., Yue L., \& Schlaich, M. 2014"Research on using CFRP Tension members in plane cables structures". The 7th International Conference on FRP Composites in Civil Engineering, Vancouver, Canada.

[13] Yue, L., Bernd, Z., \& Schlaich ,M. 2016 "Advantages of using CFRP cables in orthogonally loaded cable structures". AIMS Material Science. 3. 862-880.

[14] Olofin, I., \& Liu, R. 2016 "Numerical modal analysis of a suspen-dome with CFRP cable-strut system". ASME Journals: Series Modelling A. 8. 13-24.

[15] Olofin, I., \& Liu, R.2017 "Structural Optimization of Beijing Gymnasium Suspen-dome with CFRP (CFRP) cable". Scientific Herald of the Voronezh State University of Architecture and Civil Engineering. 36.106-115.

[16] Olofin, I., \& Liu, R. 2017 "Transient behavior of CFRP cable-strut system in a Suspen- dome". Civil Engineering Journal. 8. 547-555.

[17] Olofin I, and Liu,R. 2019 A study on the ultimate bearing capacity of CFRP cable-strut system in a suspen dome ,The Civil Engineering Journal. 46. 555-565. DOI 10.14311/CEJ.2019.04.0046

[18] Olofin, I., \& Liu, R.2020 "Research on the Static Behaviour of a Suspen Dome with CFRP (CFRP) Cable-strut System". Iranian Journal of Science and Technology, Transactions of Civil Engineering. DOI 10.1007/s40996-020-00488-5(In press).

[19] Meier ,U.2012 "CFRP cables: Why? Why not? What if?" Arabian J.SCi.Eng. 37.399-411.

[20] GBJGJ7-2012. "Technical specification for space frame structure". Chinese planning press, Beijing (In Chinese).

[21] GBJGJ257-2012. "Technical specification of cables structures". Chinese planning press, Beijing (In Chinese). 
Article no. 34

CIVIL

ENGINEERING

JOURNAL

[22] Kang, W., Chen, Z., Lam, H., \& Zuo, C. 2003“Analysis and design of the general and outmost ring stiffened suspen-dome structure”. Engineering structures. 25. 1685-1695.

[23] ANSYS.2008 "Release 10.0 Documentation for Ansys", USA.

[24] Guo, J. M., Dong, S. L., \& Yuan, X. F. 2012"Research on static property of suspen-dome structure under heap load". Advanced Steel Construction. 8.137-152. 